\title{
Conceptual framework of computer application for promoting tsunami evacuation route
}

\author{
Juliana Fisaini ${ }^{1,2 *}$, Yunita Idris ${ }^{1,2}$, and Nazriatun $\mathrm{Nisa}^{2}$ \\ ${ }^{1}$ Civil Engineering Department, Universitas Syiah Kuala, Jalan Tgk. Syech Abdurrauf No. 7 Darussalam, Banda Aceh 23111, \\ Indonesia \\ ${ }^{2}$ Tsunami and Disaster Mitigation Research Center (TDMRC), Universitas Syiah Kuala, Jl. Hamzah Fansuri No.8, Kopelma \\ Darussalam, Kota Banda Aceh 23111 Indonesia
}

\begin{abstract}
Disaster resilient is one of development priority in Indonesia. Programs related disaster risk reduction have been considered as important agenda by government and community, especially in cities that hit by earthquake and tsunami. Serious games have been used in many fields, including disaster management. This paper aims to introduce the conceptual framework of a computer application for promoting tsunami evacuation route in Baitussalam, Aceh Besar, Indonesia. The computer application is built based on serious games concept. Activity Theory-based Model of Serious Games (ATMSG), which consist of the gaming activity, the learning activity and the instructional activity in designing process, employed as the methodology to build the framework. The result present ini Serious Game diagram which explain the activities in the game. The activities deliver through scenarios which categorized based on land used and activities of the local community.
\end{abstract}

\section{Introduction}

The devastated Indian Ocean tsunami in 2004 has brought the awareness of disaster risk reduction for the government of Indonesia and international community. Efforts on implementing disaster risk management programs have become important agenda. It can be seen from the shift of paradigm in disaster management in the recent decades. Before, disaster management focused on emergency response. Nowadays, disaster management is focusing on increasing the awareness of the communities in every possible aspect [1]. Including designing and creating tsunami evacuation route plan (network). It has significant role for people who live in coastal areas which is tsunami-prone areas and vertical evacuation building (escape building) is not available.

However, 16 years after tsunami hit the city, the local community has lack of information regarding the network of tsunami evacuation route. The new residents have come to occupy areas prone to tsunami. The growth of communities because of new residents make them more vulnerable [2] because many part of the communities that have never experienced the tsunami, the greater number of people settled in high-risk area, the higher the probability of fatalities because of the disaster. The larger population of people living in highrisk areas, the higher the probability of death.

This study conducts in Kecamatan Baitussalam, Aceh Besar, Indonesia. This area is located in the coastal area, situated directly adjacent to Andaman Sea and hit by India Ocean tsunami in 2004. No vertical evacuation building is built in this area until now. The only way to evacuation from tsunami in this area is through tsunami evacuation route to reach the green area.

Besides, this abandoned neighbourhood due to 2004 Indian Ocean tsunami has been replaced by the new residential area. Several residential areas have been developed in this area, some of them are very close to the coast. This phenomenon cause fear that the new comers to this area who are not familiar with their neighbourhood situation. Thus, it is important to promote the tsunami evacuation route to this community. In some level, the knowledge regarding disaster and tsunami evacuation route contribute in evacuating people and reach the safe area in time [3].

In early of 2020, the world facing the pandemic situation making it hard to conduct drills or simulation for tsunami disaster which needed many people to get together at the same place. At the same time, disaster keep on occurring, which makes the community twice more vulnerable. Serious game can be used as an alternative option to conduct drill or simulation to increase the awareness of the community.

This paper aims to introduce the conceptual framework of a computer application for promoting tsunami evacuation route. The computer application is built based on serious games concept, which the main purpose is to deliver implicit messages through entertainment [4]. In this case, promoting tsunami evacuation routes in a coastal area and increasing the awareness of disaster preparedness during playing a game. In addition, this media also supports the efforts to

\footnotetext{
${ }^{*}$ Corresponding author: j.fisaini@unsyiah.ac.id
} 
sustain the campaign of disaster risk reduction during Covid-19 pandemic.

\section{Literature review}

\subsection{Serious games on disaster management}

Serious games have been known as one of the tools that can be used to introduce and learn something, including in the field of disaster mitigation [4]. Besides, it is also managed as a tool to increase the awareness and knowledge of the community [5]. Several serious games related to disaster have been developed [5] [6][7].

Serious games related to geological hazard are more likely to be found. Meester [8] developed "Disaster in my Backyard" to introduce 5 important topics regarding disaster management which consist of situational awareness, decision-making, coordination and communication, planning, and rescue. Mossoux et al [6] created a board game named Hazagora which aim to raise the awareness about geohazards and disaster risk reduction strategies. The purpose of the game is to develop a resilient community in the face of periodic geological hazards. This game is design based on reality which displays a volcanic island divided into different land cover areas. Multiplayer game 5 to 10 people. Wang et al [9] has developed Defying Disaster, a 2D side scroller serious game designed to teach people how to prepare for and handle an earthquake. Based on test play to 30 persons, the participants believe that learning about disaster topic through serious game is more effective that reading materials. Gampell et al [7] explored disaster video games in two New Zealand museums named Te Papa in Wellington and Quake City in Christchurch, named Quake Safe House (QSH).

In addition, serious games in hydrometeorological hazards has been attracted researchers to involve in the field as well. Meng-Han Tsai [5] created Battle of Flooding Protection, a serious game to educate disaster prevention and Delima [10] built DisCoord, a serious game first implemented in the landslide-and flood-prone and useful as a public pedagogy intervention as they bring different forms of knowledge together in a public space and facilitate co-learning.

Hawthorn et al [4] reviewed and collected data of serious games with main purposes related to Tsunami Risk Communication. Academic database and nonacademic source i.e. YouTube and Google Play Store includer. Based on the search, several serious games such as Disaster Master (undated), Stop Disasters, Earth Girl and Earth Girl 2, Disaster Hero (Legacy Interactive) and Tanah - The Tsunami and Earthquake Fighter are listed. This work indicates that the demand of serious games in the field of disaster has amplified with the possibility of increasing people awareness of disaster damages and escalating the frequency of disaster.

\subsection{Disaster resilience}

Since the devastated tsunami in 2004, the paradigm of disaster management in Indonesia has shifted from focusing on emergency response to preparedness in coping the disaster [11]. This changing is followed by mainstreaming disaster management into every level. So that, disaster management is not only the government responsibility, but also NGO - Non Government Organization, private sector and the communities. This is in accordance with the goals of Sendai Framework for Disaster Risk Reduction (SFDRR), to build community that is resilient to disasters [12].

Based on the UNDRR terminology, resilience is the ability of a system, community or society exposed to hazards to resist, absorb, accommodate, adapt to, transform and recover from the effects of a hazard in a timely and efficient manner, including through the preservation and restoration of its essential basic structures and functions through risk management.

Community disaster resilience (CDR) is the capability of the community to be able to recover in coping the disaster [13]. In the recent year, the definition of community disaster resilience not only concentrating on the ability of the community to recover from the disaster but starting to include readiness, mitigation and disaster adaptability within it [13]. The resilience of community toward disaster will be able to achieve by improving their capacity and knowledge regarding disaster in their neighbourhood. Education and capacity building to enhance a better understanding of disaster hazard and disaster risk at their neighbourhood can be perform in disaster prone community [12].

\subsection{Land use, activity center and route choice model}

Tsunami evacuation routes plays significant roles in the prone tsunami area with no vertical evacuation building available such as in District of Baitussalam, Aceh Besar, Indonesia. It becomes the only alternative of tsunami mitigation instrument. Planning of tsunami evacuation route covers both route for vehicles and pedestrians [14], however in South East Asia countries, where most road infrastructure are narrow, the effort of tsunami mitigation mostly by running and walking (pedestrian) [15]. L"ammel et al (2011) also agree that mass evacuation become a complex problem in transport planning [15].

When the disaster come, there is an urgent to evacuate people in large number from vulnerable area (red zone) to the safe area (green zone) to reduce the disaster risk [15]. In evacuating people, especially in the area with no vertical evacuation shelter, road assigned as tsunami evacuation routes become very important. In planning of evacuation route, road network which perpendicular to the coastal line turn itu the first consideration [16] and the shortest route to reach safe area or evacuation shelter. In transport planning, the shortest route is not only determined by the shortest distance [15] but also consider the shortest travel time. This theory is known as Nash Equilibrium Approach [15]. Besides, the closest evacuation places and the shortest routes also able to be calculated using the Dijkstra method [17].

Researches on route planning in several countries with high tsunami potential have been performed. Wargadalam et al stated that lack of information of shelter and tsunami evacuation route relatively increase the number of the victims based on the tsunami incident 
in Pangandaran, Indonesia. Lack of information of shelter location and evacuation routes lead to traffic congestion during the mitigation process [18]. Takabatake et al [14] simulated the mobility behaviour of local residents and tourists in tsunami evacuation. In this model, the behaviour of local residents and visitors are differentiate based on their familiarity to the city of Kamakura, Japan. It is assumed that local residents have information of shortest route to evacuate and know the location of shelters, while visitors follow the crowds in evacuation process and run to higher land. Result shows that in the bottle neck area wherepassed by visitors during evacuation are congested and the speed of evacuation decrease dramatically.

Scheer et al [19] developed generic framework for tsunami evacuation planning. Several essential items for tsunami evacuation map listed in the framework, i.e location of evacuation shelter, travel time to reach the shelter and safe place or green zone of tsunami hazard. In details, the tsunami evacuation map should exhibit the direction to escape, the availability of roads and/or major paths (evacuation routes) in this direction, information of the number of people that will use these evacuation routes simultaneously, the minimum travel speed (of the evacuees) to count with and the distance towards the next safe destination (including locations of horizontal and vertical shelters) [20].

Álvarez [3] explained about the utilize of pedestrian di Kota Iquique, Chili which potentially obstruct evacuation process if tsunami hit the city. Several reasons of this possibility are physical condition of pedestrian surface, lack of pedestrian maintenance, complex design of pedestrian i.e. stairs and the utilization of pedestrian for restaurant dan parking area. Sahal et al explores the alternative of pedestrian evacuation planning in the coastal area of Rivera River, French Mediterranean coast. Using RouteFinder and SimWalk to identify the routes to the shelter from the beach and estimate travel time by walking to the shelter [21]. Hector R. Lim Jr develop a model of route choice behaviour of evacuees in highly urbanized area based on the case study in Bagong Silangan, Quezon City, Philippines [22].

\section{Methodology}

\subsection{Study area}

This study is located in Kecamatan Baitussalam, Aceh Besar, Indonesia, with an area of $20.84 \mathrm{~km} 2$, which is divided into 13 (thirteen) villages with population of 19,264 people. This area is mostly located in the coastal area as shown in Fig. 1. The targeted location are in Kajhu Village and Cadek Village.

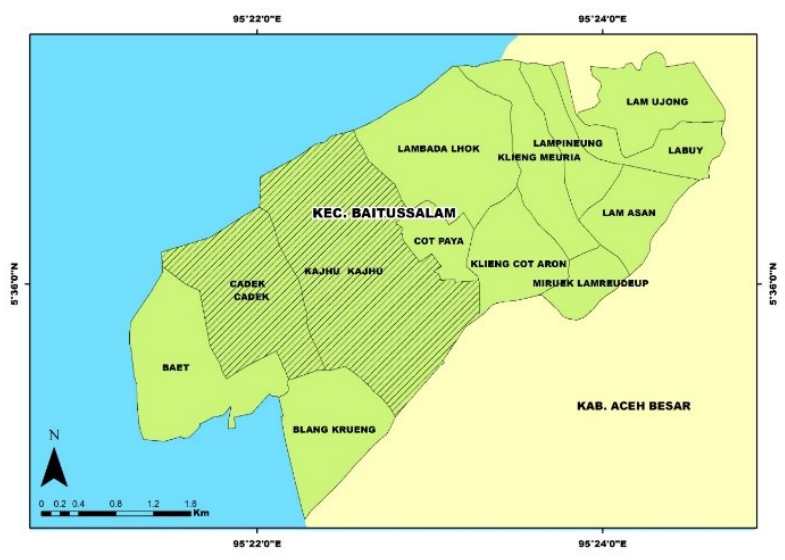

Fig. 1. Study Location

\subsection{Framework development process}

The framework development of this computer application is adapted from the work of Morschheuser et al [23]. This work reviewed serious game models and proposed a method to develop a serious game. The method consists of seven phases as shown in Fig. 2.

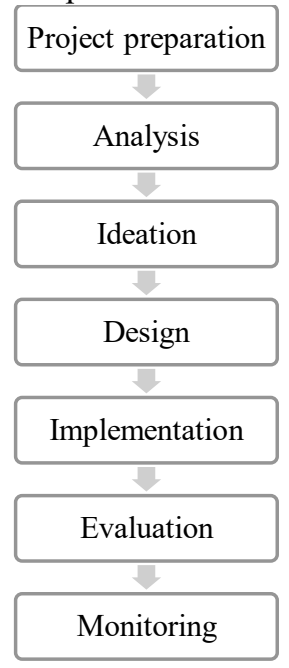

Fig. 2. Design game method (morschheuser).

The seven phases consist of Project preparation, Analysis, Ideation, Design, Implementation, Evaluation and Monitoring. We modified the phases by adding promotion phase. Promotion has significant role in disaster management game since the targeted users are from large community. All people who live and visit tsunami prone are required to know the existing of the game.

Since the purpose of the game is to introduce tsunami evacuation route, we deliver the insight of tsunami evacuation route through several scenarios. Scenarios cover areas based on land used of the area, for example education, commercial, residential and worship center.

The framework will be implemented in the form of computer application especially computer video game with single player. The user, namely targeted group, will experience the realm in the gamec as they visited the location since the setting of the serious game is develop based on the reality of Kecamatan Baitussalam, Aceh Besar, Indonesia. This consideration is chosen to fulfil 
the general purpose of serious game, to simplify the reality.

\subsection{Serious game design}

In designing a serious game, the general network of the game plays an essential process of development. The initial network of the game story considers as the groundwork in creating serious game diagram. In order to establish the development process systematically, a serious game design methods/framework is employed. Game design framework used to be a tool to analyse games. The rise of framework development to analyse and develop a game has been began in 1960s. LeBlanc, Hunicke and Zabek introduce MDA (MechanicsDynamics-Aesthetics), a framework focuses on the design of games for entertainment [24]. Later on in 2015, [24] presented DPE (Design - Play - Experience) framework. The framework depicts the sub components of serious game design, including the Learning, Storytelling, Gameplay, and User Experience layers.

In the domain of serious games, several methods and frameworks have been introduced to analyze and design the game. Each method has advantages and disadvantages. Recently, ATMSG was establish to assist researchers from multidisciplinary field to analyse and design the serious game [25].

The framework is developed based on Activity Theory-based Model of Serious Games (ATMSG), which consist of the gaming activity, the learning activity and the instructional activity in designing process [25]. This method considers the role of users as well as the serious game play the similar position in delivering lessons embedded in the application, which named instructional activity. Instructional activity consists of intrinsic instruction (task in the serious game) and extrinsic instruction (the instruction that informed by instructor).

The process serious game design using ATMSG employs 4 steps which classified into 2 phases. First phase named Analyze Activities which is the first steps of the process, to identify and describe the activities in the activity network. Second phase named analyze action, consist of step 2 - represent game sequence, step 3 identify action, tool and objectives dan step 4 provide description of the implementations.

In order to build the serious games, several stages are employed. These stages derived from the methods used. In general, it is necessary for serious game designers to determine the objectives of the serious game in the first place. The serious game named SG EvaNami - Promoting Tsunami Evacuation Route aims to provide virtual drills to endorse the existing tsunami evacuation network to the inhabitants around tsunami prone area. The game is developed to create the awareness of tsunami risk to the residents in the targeted area.

\subsection{Coordination of stakeholders}

In order to achieve the goal, coordination among stakeholders become an important aspect. To acquire the support in collecting data, we cooperate with several stakeholders such as head of district, representatives from Regional Board for Disaster Management in Aceh Besar, Indonesia (BPBD Aceh Besar), and two headmen of the targeted area. In consequence, these partnerships intensify the public involvement in developing the framework. The collaboration among stakeholders also stimulates the public participation.

In preparation of developing the framework, discussion with the headmen and head of district has been initiated. The main topic of the discussion is to measure the tsunami preparedness in Baitussalam area. To quantify the information, a questionnaire survey is implemented. The questionnaire survey will be explained in the next chapter.

Furthermore, to obtain the information regarding existing tsunami evacuation network in Baitussalam area, cooperation with Regional Board for Disaster Management in Aceh Besar, Indonesia (BPBD Aceh Besar) is established. The representatives of local government agency who responsible for disaster management hand over the existing tsunami evacuation routes in the area of Regency Aceh Besar. It is believed that the existing tsunami evacuation routes in Aceh mostly not relevant to the current condition. Since these data is employed as the foundation of the design game, to guaranty the accuracy of the data, we organized a tsunami evacuation routes survey.

\subsection{Tsunami evacuation route survey}

The tsunami evacuation routes survey is divided into two categories: survey of the properness of the existed tsunami evacuation network and survey of the alternative tsunami evacuation route for serious games scenario. The survey of the existence of existed evacuation route aims to ensure that the evacuation routes listed on the map are still available and usable. It is essential to assess the availability and quality of the available network to minimize the fear of existing network does not meet the requirements of tsunami evacuation routes characteristics or the existed tsunami evacuation routes remain in appropriate condition.

In addition to utilizing the existing tsunami evacuation routes, this research also maps several alternative routes that can be used in the event of tsunami disaster. The alternative tsunami evacuation route was chosen based on an imaginary line built from the tsunami wave flow boundary that occurred in 2004. So that the selected meeting point is not in tsunami prone zone.

This survey conducted to ensure that the specified meeting points are located in tsunami green zone. The alternative routes and selected meeting points embed in the serious game EvaNami through several scenarios.

The mapping of the alternative tsunami evacuation route conducted using android-based application, Avenza Maps. This application used to map the paths traversed by surveyors. This application recorded the distance and travel time to the designed meeting points. The survey is conducted by 6 surveyors within 3 days. 


\subsection{Tsunami preparedness questionnaire survey}

To comprehend the preparedness of the community toward tsunami, the questionnaires were delivered. In the first phase, the questionnaires distribute through an online survey platform named Google Form. We shared the survey through Facebook and WhatsApp. Due to the limited access of targeted community to social media, 4 surveyors were sent to the targeted area for the second phase of questionnaire survey. 30 people were interviewed regarding their readiness of facing tsunami in the future.

The questionnaires were adapted from Individual and Household Preparedness Framework in Anticipating Natural Disasters, an assessment developed by Indonesian Institute of Sciences (LIPI) in collaboration with UNESCO/ISDR in 2006 [26] [27]. This framework aims to measure the level of knowledge/capacity, vulnerability and readiness of community in dealing with earthquake and tsunami. The questions comprise of 3 groups which consist of the characteristics of participants including experience of the 2004 Indian Ocean Tsunami in the area and duration of residency in the area, knowledge related to disaster especially tsunami and household disaster preparedness plan.

\subsection{Evaluation process}

The process of game evaluation is conducted through a Focus Group Discussion (FGD) involved stakeholders and community representatives. The evaluation is done by conducting pre-test, test play, and post-test. Pre-test and post-test are questionnaire-based test.

\section{Result and discussion}

The designed computer application aims to promote tsunami evacuation route. The application is built based on the concept of serious game and route choice model for tsunami evacuation.

\subsection{Tsunami evacuation route in Baitussalam Aceh Besar}

Regional Board for Disaster Management in Aceh Besar, Indonesia revealed that one of our targeted area has been assigned as one of Desa Tangguh Bencana (Resilient Village). Desa Tangguh Bencana (Destana) is a national government program through Indonesian National Board for Disaster Management (BNPB). The program is built the capacity of the village to be able to comprehend the disaster hazard in their area and be able to organize the human resources in the community to decrease the vulnerability as well as increase the capacity to reduce the disaster risk. Thus, our project is believed to have synergy to the existed government program in the area since we have similar goal: to create resilient community in disaster prone area.

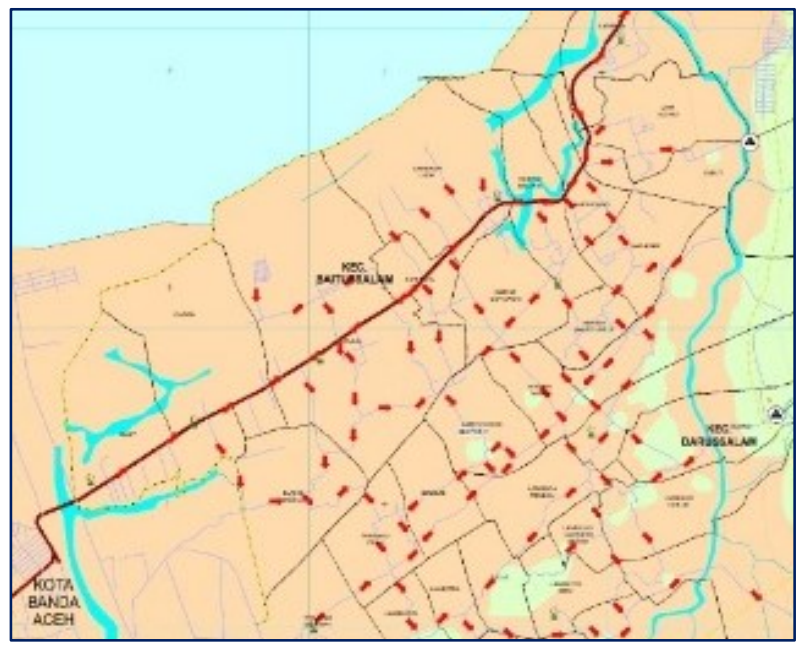

Fig. 3. Tsunami Evacuation Route.

Source: BPBD Aceh Besar, Indonesia

Furthermore, to support the SG EvaNami framework development, the Regional Board for Disaster Management in Aceh Besar, Indonesia (BPBD Aceh Besar) provided the existed tsunami evacuation map of Kecamatan Baitussalam, Aceh Besar, which shown in Figure 1. Figure 1 display the tsunami evacuation route existed in Kecamatan Baitussalam, Aceh Besar Indonesia. Tsunami evacuation route signs appears to direct people to avoid the coastal area. The evacuation should be done by running vertically to the coastal line. However, the information of tsunami evacuation shelter (meeting point) and the shortest routes are not available. There also no information regarding the green zone of tsunami. This map is not available in the public area of Baitussalam, Aceh Besar.

\subsection{Game objective}

Every serious game has specific purpose to be achieved. In general, serious game in the field of disaster aims to improve the awareness of disaster risk and resilience. Several developed serious games have very specific goals, for example DisCoord aims to educate the community about the landslide and flood-prone [10], Defying Disaster - a 2D side scroller serious game designed to teach people how to prepare for and handle an earthquake [24] and some others mentioned in Introduction. It is also applied to SG EvaNami, which framework is introduce in this paper, the SG EvaNami is designed with the purpose to promote tsunami evacuation routes in the coastal area. In addition, the framework of SG EvaNami also linked to website EvaNami, where the information of tsunami knowledge is available. Besides, the website also provides quiz to test the preparedness of community in facing tsunami in the future. The website can be accessed for free by the community. This digital media also benefit to forward the information regarding disaster to the next generation. In addition, in the Covid19 pandemic era, which physical distance is promoting and the crowd is prohibited [28], it is can be used as a virtual drill for tsunami evacuation. 


\subsection{Targeted users}

Development of serious games with specific purpose mostly associate with stakeholders in the field. SG EvaNami which focus on promoting tsunami evacuation routes have targeted users whom have been determined. At the first phase, the serious game intend to be introduce to stakeholders in related sector, such as local government, BPBD Aceh Besar, researchers, academicians, and headmen of the targeted area. In the next phase, this drill is expected to be used by the community from various ages including students and elderly with computer dan smartphone literacy.

Children under 12 years old who are able to read and operate computer or and smartphone will be able to play SG EvaNami under supervision of parents. There is a scenario in the SG EvaNami which placed the school as the base area. This scenario represents the education center/land used as disaster prone area Teenagers older than 12 years old, adult both men and women, as well as elderly are assumed to have activities in the residential area, commercial area and worship center. Therefore, the proposed scenarios in the framework consider these activity center as the basis area or starting points in the scenarios.

\subsection{Conceptual framework of SG EvaNami}

The conceptual framework of SG EvaNami - Promoting Tsunami Evacuation Route is presented in Fig. 4. The framework displays the development process of the serious games divided into six stages. The first stage is Ideation. In this stage, we explore general plan of the serious game and identify data need for the game development.

The second step, context and user analysis. Context analysis begin by conducting preliminary survey. The preliminary survey consists of community capacity toward disaster survey which aim to identify the level of community resilience of targeted community (game user). Furthermore, in this stage we also perform validation of imaginary line of tsunami inundation boundary and data collection of existing tsunami evacuation route and survey alternative tsunami route. The third stage is the design process. We employ ATMSG method to design the serious game. Game development is implemented by using Unreal Engine.

The fifth stage is evaluation. The evaluation process is done through a focus group discussion involved stakeholders and community representatives as targeted user. The activity of evaluation cover pre-test, test play, and post-test. Questionnaires regarding the knowledge of tsunami evacuation route distributes to the FGD participants before and after playing the game to test the impacts of playing the game for players and user experience of the game. Participants are requested to present their opinion in order to develop better version of the game. The last stage is Promotion. This activity intends to socialize the media to the public. The promotion is conducted by sharing the information through various platform.

\subsection{Proposed evacuation route employed in SG EvaNami}

In the design process, scenarios in the game is determined by considering the center of activity of the community. In general, people have do go to school to get education. Women in the area is dominated by stay at home mother, which brought us to the consideration mostly women will go to shopping area (commercial area). Furthermore, since the targeted area is in Aceh where the Islamic sharia law is implemented, we add mouse or worship center as one of many scenarios. Consequently, five scenarios are proposed, which 5 location Residential Area in Desa Cadek, SD Mon Singet, Pasar Kajhu, Pasar Ikan Lam Ujung, Perumahan di Lambada Lhok and Mesjid Labuy as the basis area in the scenarios. These areas are chosen due to the location close to the coastal area and hit by tsunami in 2004.

Furthermore, the shelter or meeting point for evacuation in each scenario is determine. The location of meeting point is decided base on the tsunami evacuation shelter criteria or located in the green zone from tsunami. Grounded on the two locations, we proposed several tsunami evacuation routes to connect the red zone to the green zone.

Fig. 5 shows the proposed evacuation routes with several alternatives. The information of road network acquired from Google Map. Surveyors did site visit (survey) to ensure the quality of the road meet the characteristics of tsunami evacuation routes, at least for pedestrians. By using the concept of route choice model which the best route is considered by the shortest route [15]. Besides, several alternatives provided which have possibility that during the congested hours, the alternative routes serve shorter time to reach the evacuation shelter. This also derive from the concept of route choice model [22].

Besides the shortest path and shortest travel time to reach the evacuation shelter, another consideration take into account in planning the evacuation route is the route should be perpendicular to coastal lines [16] and the coordinate of the shelter area have to be in the green zone of tsunami (based one tsunami flow in this location in 2004). 


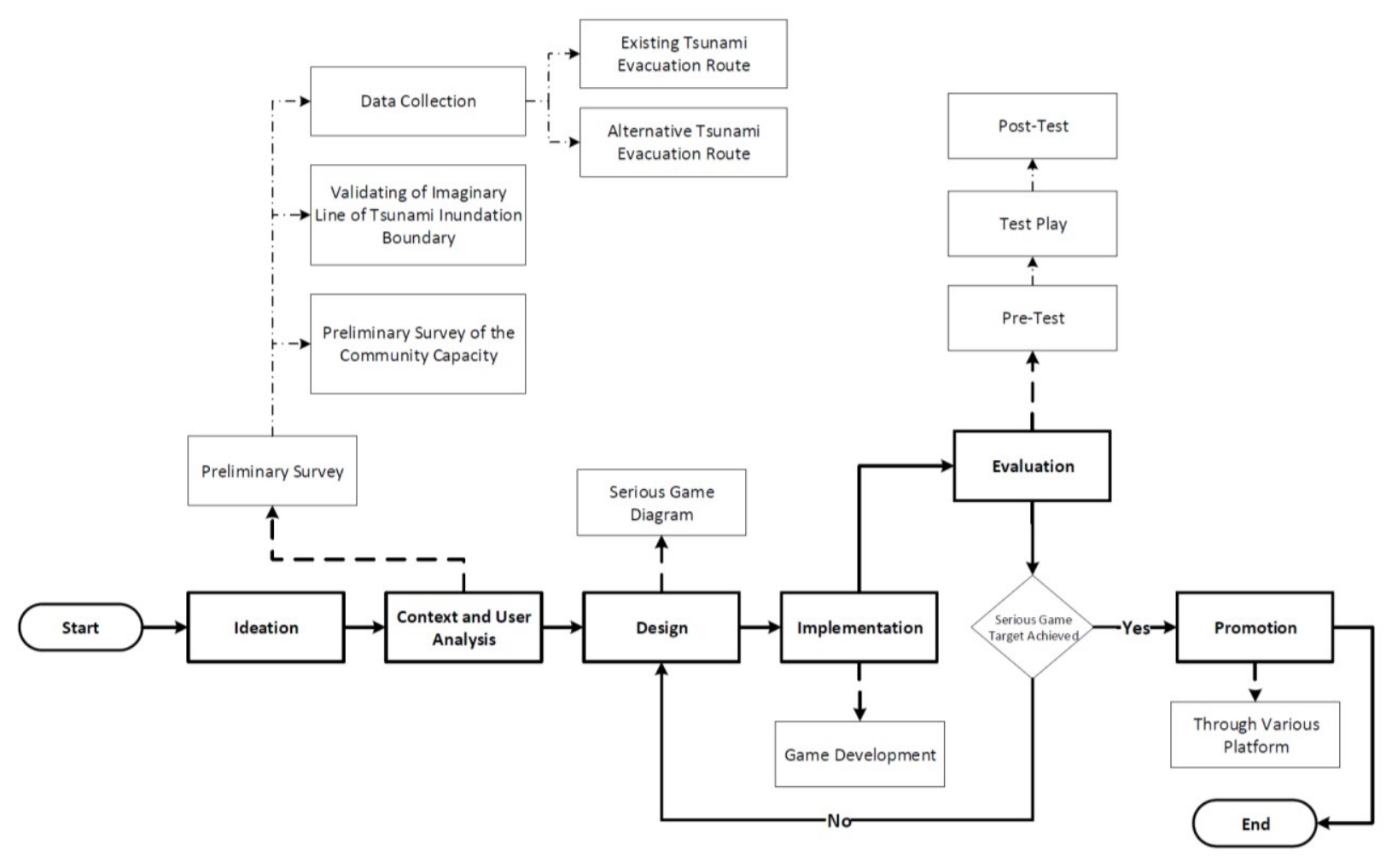

Fig. 4. Conceptual framework of SG EvaNami.

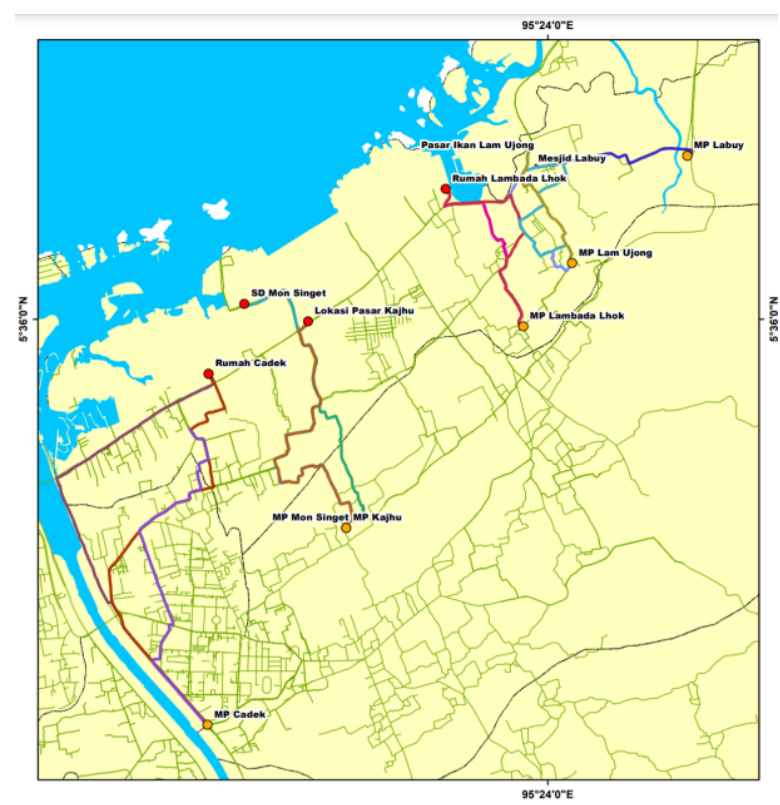

Fig. 5. Proposed tsunami evacuation route and Meeting Point in SG EvaNami.

\section{Conclusion}

To conclude, this paper presents the conceptual framework of a computer application. The computer application includes in a computer video game aims to promote tsunami evacuation route. The framework is develop based on existed methods of developing a serious game with some modification to achieve the main goal of game. Besides, the concept of land used, route choice model, and tsunami evacuation route requirements employed. It is expected that the serious game will be able to be a tool in promoting tsunami evacuation route to both for recent community and the next generation. This computer application preserves as a drill in disaster mitigation during Covid19 pandemic, where large scale social restriction is implemented.

The conceptual framework describes the whole process of developing the game. It consists of six stages, from ideation to socialization. In developing the serious game, stakeholders are involved. The community capacity in tsunami preparedness are analyzed through questionnaires survey. In designing scenarios, tsunami evacuation route survey and alternative road are explored, and the evaluation process involved stakeholders as well as targeted users to get the feedback for the game. It is believed that this computer application advances the benefit of serious game in disaster management field.

\section{References}

1. B. Ryan, K. A. Johnston, M. Taylor, and R. McAndrew, Int. J. Disaster Risk Reduct. 49, 101655 (2020)

2. B. Adu-Gyamfi and R. Shaw, Int. J. Environ. Res. Public Health 18, (2021)

3. G. Álvarez, M. Quiroz, J. León, and R. Cienfuegos, Nat. Hazards Earth Syst. Sci. 18, 2027 (2018)

4. S. Hawthorn, R. Jesus, and M. A. Baptista, Int. J. Serious Games 8, 21 (2021) 
5. M. H. Tsai, Y. L. Chang, J. S. Shiau, and S. M. Wang, Int. J. Disaster Risk Reduct. 43, 101393 (2020)

6. S. Mossoux, A. Delcamp, S. Poppe, C. Michellier, F. Canters, and M. Kervyn, Nat. Hazards Earth Syst. Sci. 16, 135 (2016)

7. A. V. Gampell, J. C. Gaillard, M. Parsons, and L. Le Dé, Int. J. Disaster Risk Reduct. 49, 1 (2020)

8. K. Meesters, L. Olthof, and B. Van de Walle, Proc. Eur. Conf. Games-Based Learn. 2, 714 (2014)

9. Y. Chen, T. Wang, X. Wu, and Y. Xie, 109 (2015)

10. G. Delima, L. Jacobs, M. Loopmans, M. Ekyaligonza, C. Kabaseke, M. Kervyn, and K. Mertens, Int. J. Disaster Risk Reduct. 60, 102303 (2021)

11. H. Fahlevi, M. Indriani, and R. S. Oktari, Jamba J. Disaster Risk Stud. 11, 1 (2019)

12. A. A. Shah, R. Shaw, J. Ye, M. Abid, S. M. Amir, A. K. M. Kanak Pervez, and S. Naz, Int. J. Disaster Risk Reduct. 34, 165 (2019)

13. R. S. Cox and M. Hamlen, (2015)

14. T. Takabatake, T. Shibayama, M. Esteban, H. Ishii, and G. Hamano, Int. J. Disaster Risk Reduct. 23, 1 (2017)

15. G. Lämmel, 1 (2011)

16. F. Kitamura, D. Inazu, T. Ikeya, and A. Okayasu, Int. J. Disaster Risk Reduct. 45, 101519 (2020)

17. R. D. Prayogo and S. A. Karimah, 2020 8th Int. Conf. Inf. Commun. Technol. ICoICT 20200
(2020)

18. R. Wargadalam, H. Nakanishi, Y. Vidyattama, J. Black, and Y. Suenaga, IOP Conf. Ser. Earth Environ. Sci. 630, (2021)

19. S. Scheer, A. Gardi, R. Guillande, G. Eftichidis, V. Varela, B. de Vanssay, and L. Colbeau-Justin, Handbook of Tsunami Evacuation Planning (2011)

20. S. J. Scheer, V. Varela, and G. Eftychidis, Phys. Chem. Earth 49, 79 (2012)

21. A. Sahal, F. Leone, and M. Péroche, Nat. Hazards Earth Syst. Sci. 13, 1735 (2013)

22. H. R. Lim, M. B. B. Lim, and M. Piantanakulchai, Asia Pacific Manag. Rev. 24, 98 (2019)

23. B. Morschheuser, K. Werder, J. Hamari, and J. Abe, Proc. Annu. Hawaii Int. Conf. Syst. Sci. 2017-Janua, 1298 (2017)

24. Y. Chen, T. Wang, X. Wu, and Y. Xie, 109 (2015)

25. M. B. Carvalho, F. Bellotti, R. Berta, A. De Gloria, C. I. Sedano, J. B. Hauge, J. Hu, and M. Rauterberg, Comput. Educ. 87, 166 (2015)

26. T. Triyono, W. Widayatun, and D. Hidayati, (2011)

27. LIPI, UNESCO, and UN-ISDR, Kajian Kesiapsiagaan Masyarakat Dalam Mengantisipasi Bencana Gempa Bumi \& Tsunami (2006)

28. J. Brinkman and K. Mangum, (2020) 